Published in final edited form as:

Biochemistry. 2020 February 04; 59(4): 552-562. doi:10.1021/acs.biochem.9b00919.

\title{
Ligand-Guided Selection with Artificially Expanded Genetic Information Systems against TCR-CD3 $\varepsilon$
}

\author{
Hasan Zumrut, \\ CUNY Graduate Center, New York, New York \\ Zunyi Yang, \\ Firebird Biomolecular Sciences, LLC, Alachua, Florida \\ Nicole Williams, \\ CUNY Graduate Center, New York, New York \\ Joekeem Arizala, \\ CUNY Graduate Center, New York, New York
}

Sana Batool,

The City University of New York, Bronx, New York

Steven A. Benner,

Firebird Biomolecular Sciences, LLC, Alachua, Florida, and Foundation for Applied Molecular Evolution, Alachua, Florida

Prabodhika Mallikaratchy CUNY Graduate Center, New York, New York, and The City University of New York, Bronx, New York

\section{Abstract}

Here we are reporting, for the first time, a ligand-guided selection (LIGS) experiment using an artificially expanded genetic information system (AEGIS) to successfully identify an AEGISDNA aptamer against $\mathrm{T}$ cell receptor-CD3 $\varepsilon$ expressed on Jurkat.E6 cells. Thus, we have effectively combined the enhanced diversity of an AEGIS DNA library with LIGS to develop a superior screening platform to discover superior aptamers. Libraries of DNA molecules from highly diversified building blocks will provide better ligands due to more functional diversity and better-controlled folding. Thus, a DNA library with AEGIS components (dZ and dP) was used in LIGS experiments against TCR-CD3 $\varepsilon$ in its native state using two clinically relevant monoclonal antibodies to identify an aptamer termed JZPO-10, with nanomolar affinity. Multiple specificity

Corresponding Author Phone: 347-577-4082; prabodhika.mallikaratchy@lehman.cuny.edu.

Supporting Information

The Supporting Information is available free of charge at https://pubs.acs.org/doi/10.1021/acs.biochem.9b00919.

Flow cytometric data for all mAb binding analyses, flow cytometric data for aptamer screening analysis, and affinity curves for the aptamer and its truncated variants (PDF)

The authors declare the following competing financial interest(s): S.A.B. and Z.Y. and their institutions own intellectual property related to in vitro selection with expanded genetic alphabets, including the nonstandard nucleoside derivatives used here. Several of the reagents used in this report are sold by Firebird Biomolecular Sciences, LLC (http://firebirdbio.com), which employs the indicated authors and is owned by S.A.B. 
assays using knockout cells, and competition experiments using monoclonal antibodies utilized in LIGS, show unprecedented specificity of JZPO-10, suggesting that the combination of LIGS with AEGIS-DNA libraries will provide a superior screening platform to discover artificial ligands against critical cellular targets.

Discovery of DNA aptamers against various cellular targets using an in vitro evolution platform termed systematic evolution of ligands by exponential enrichment (SELEX) was introduced in the early 1990s. ${ }^{1,2}$ Since then, this field has evolved by expanding the repertoire of targets. ${ }^{3}$ Most recently, however, unprecedented momentum in the aptamer field has occurred by the introduction of high-throughput sequencing technologies accompanied by bioinformatics, facilitating reliable, efficient, and informative sequencing of SELEX libraries. ${ }^{4-6}$ Also, utilization of unnatural nucleic acids has been generated by introducing various functional groups to nucleic acid ring moieties. ${ }^{7-11}$ This has allowed the development of a structurally expanded and diversified SELEX library. This higher structural diversity also brought us one step closer to the discovery of artificial nucleic acid ligands composed of functional groups mimicking side chains of amino acids against protein targets enabling the design of artificial ligands against cellular targets to mimic naturally existing protein-protein interactions. For example, via the addition of a range of hydrophobic side chains to naturally existing DNA bases, slow off-rate aptamers (SOMAmers) were generated, and Gold et al. reported SOMAmer ligands against a large number of human proteins with high affinities. ${ }^{12}$ Also, Hiraro and co-workers selected aptamers against IFN- $\gamma$ and VEGF-165, using the five-letter nucleic acid library. ${ }^{13}$

Benner and co-workers have developed the artificially expanded genetic systems (AEGISs), which is a biopolymer consisting of a synthetic building block in addition to natural DNA. ${ }^{14}$ Using an AEGIS-DNA library combined with laboratory in vitro evolution (LIVE), AEGISDNA aptamers were discovered against whole breast cancer cells and, later, against glypican 3 (GPC3) and anthrax protective antigen 3 (PA63). ${ }^{7,15,16}$ In these AEGIS-LIVE experiments, specific aptamer ligands were evolved using fewer selection cycles compared to entirely natural DNA libraries. While the enhancement of structural diversity by adding nonstandard bases to the randomized region of the DNA library is an essential component of LIVE, the efficient identification of high-affinity and highly specific aptamers heavily relies on screening technology, particularly when the target is a cell-surface protein.

To this end, we recently introduced a variant of SELEX termed ligand-guided selection (LIGS) to identify highly selective aptamers against membrane proteins without modifying their native functional fold. ${ }^{17-19}$ The LIGS method was developed by exploiting the evolutionary step of the competition of weak binders with strong binders. Via the introduction of stronger higher-affinity secondary ligands, such as a monoclonal antibody $(\mathrm{mAb})$, against the target of interest, LIGS could elute specific aptamers potentially enriched against the same target. So far, LIGS has successfully identified highly specific aptamers against known cell-surface proteins without modifying the cellular landscape. Utilizing LIGS, we introduced aptamers against surface IgM expressed on human B cells and TCRCD3 expressed in human T cells. . $^{37-22}$ 
Herein, for the first time, we sought to utilize LIGS combined with AEGIS-LIVE to selectively identify highly specific AEGIS-DNA aptamers against the TCR-CD3 complex expressed in human $\mathrm{T}$ cells. $\mathrm{CD} 3$ is a crucial receptor expressed on $\mathrm{T}$ cells, and it is required for $\mathrm{T}$ cell activation. Accordingly, antibodies against $\mathrm{CD} 3$ have been investigated for $\mathrm{T}$ celldirecting immunotherapies. However, the discovery of artificial ligands against TCRCD3 is challenging because of its complex structure, which consists of eight subunits with evidence of triple subunit assembly. ${ }^{23,24}$ Thus, mimicking these types of complex structures in their purified form with the objective of discovering artificial ligands is nearly impossible. Therefore, we utilized a native functional state of TCR-CD3 by performing AEGIS-LIVE against a Jurkat.E6 cell line, a cell line known to express high levels of TCR-CD3. Then LIGS was performed using two clinically relevant mAbs against TCR-CD3 to elute highly specific artificial nucleic acid ligands against TCR-CD3. We identified a highly specific artificial nucleic acid ligand, termed JZPO-10, against the CD3/TCR complex expressed on Jurkat.E6 cells with a nanomolar affinity at $37^{\circ} \mathrm{C}$.

\section{MATERIALS AND METHODS}

Cell Lines.

Jurkat (clone E6, acute T cell leukemia), MOLT-3 (acute lymphoblastic leukemia), and Toledo (non-Hodgkin's B cell lymphoma) cells were purchased from American Type Culture Collection (ATCC). Double-knockout (CRISPR-Cas9 targeting CD3 $\varepsilon$ and TRAC genes) Jurkat cells were purchased from Synthego Inc. All cell cultures were maintained in RPMI 1640 medium supplemented with either $10 \%$ or $20 \%$ fetal bovine serum (FBS) and 100 units/mL penicillin-streptomycin and $1 \%$ non-essential amino acids.

\section{DNA Synthesis and SELEX Library.}

5'-ATA GAC TGG ACT GTC GTC (N35 GACTZP library) TAG CAT CGG ATA CAG GTC- $3^{\prime} . \mathrm{N}=\mathrm{G} / \mathrm{A} / \mathrm{C} / \mathrm{T} / \mathrm{Z} / \mathrm{P}$ phosphoramidites in a 1/1/1/1/1/2 ratio. Extinction coefficient of $689250 \mathrm{~L} \mathrm{~mol}^{-1} \mathrm{~cm}^{-1}$.

\section{Chemical Synthesis and Purification of GACTZP Libraries To Support SELEX.}

All dZ- and dP-containing oligonucleotides (Table S1) were synthesized in a DNA synthesizer (ABI 394) using standard phosphoramidite chemistry on glass support (CPG). Protected dZ and dP phosphoramidites were obtained from Firebird Biomolecular Sciences LLC (www.firebirdbio.com). Standard phosphoramidites (Bz-dA, Ac-dC, dmf-dG, and dT) were purchased from Glen Research (Sterling, VA). The DNA library oligonucleotides were designed to have forward and reverse primer binding segments (each 18 nucleotides in length) with a random region (35 nucleotides) containing GACTZP (six nucleotides) in a 1/1/1/1/1/2 ratio. Coupling times were $120 \mathrm{~s}$.

To remove protections, CPG-bound DMT-off DNA molecules were incubated with an acetonitrile/triethylamine mixture $[1 / 1(\mathrm{v} / \mathrm{v}), 1.5 \mathrm{~mL}]$ for $1 \mathrm{~h}$ at room temperature. Following removal of the supernatant, the CPG-bound oligonucleotides were treated with an additional $1.5 \mathrm{~mL}$ of a triethylamine/acetonitrile mixture $[1 / 1(\mathrm{v} / \mathrm{v})]$ overnight at room temperature. After removal of the supernatant, the CPG-bound oligonucleotides were incubated with 1.0 
$\mathrm{mL}$ of DBU ( $1 \mathrm{M}$ in anhydrous acetonitrile) at room temperature for $18 \mathrm{~h}$ to remove the protecting groups on $\mathrm{dZ}$. After the removal of DBU and the acetonitrile solution, the CPGbound oligonucleotides were retreated with $1 \mathrm{~mL}$ of concentrated ammonium hydroxide (28-33\% $\mathrm{NH}_{3}$ in water) at $55^{\circ} \mathrm{C}$ overnight (10-12 h). The oligonucleotides were purified by denaturing polyacrylamide gel electrophoresis (PAGE) (7 M urea) and desalted by Sep-Pac Plus C18 cartridges (Waters). All Cy3-labeled dZ- and dP-containing aptamer candidates were synthesized, deprotected, and purified in house via the same method. The Cy3-labeled forward primer ( $5^{\prime}$-Cy3-ATA GAC TGG ACT GTC GTC- $\left.3^{\prime}\right)$ and the biotinylated reverse primer ( $5^{\prime}$-biotin-GAC CTG TAT CCG ATG CTA- $3^{\prime}$ ) were purchased from Integrated DNA Technologies Inc. (IDT, Coralville, IA).

\section{Antibodies.}

Anti-CD3 monoclonal antibodies UCHT1 (mouse anti-human, isotype IgG1, catalog no. BE0231), OKT3 (mouse anti-human, isotype IgG2a, catalog no. BE0001-2)- and the antiCD28 monoclonal antibody (mouse anti-human, isotype $\operatorname{IgG} 2$ a, clone 9.3, catalog no. BE0248) were obtained from BioXCell. Alexa Fluor 647- and Alexa Fluor 488-conjugated goat anti-mouse IgGs (catalog no. 115-605-062) were obtained from Jackson ImmunoResearch Laboratories Inc.

\section{Buffer Formulations.}

Cell suspension buffer (CSB) was formulated with RPMI 1640 medium containing 200 $\mathrm{mg} / \mathrm{L}$ tRNA and $2 \mathrm{~g} / \mathrm{L}$ BSA. Wash buffer and denaturing buffer were both RPMI-1640.

\section{AEGIS-Cell SELEX.}

Target Jurkat.E6 cells were analyzed for expression of TCR-CD $3 \varepsilon$ utilizing respective antibodies via flow cytometry. The first round of SELEX was performed by denaturing 10 nmol of a PAGE-purified ZP-containing DNA library suspended in RPMI by heating for 10 $\min$ for $95^{\circ} \mathrm{C}$. The denatured library was folded for $1 \mathrm{~h}$ at $37^{\circ} \mathrm{C}$ and incubated with $10 \times$ $10^{6}$ Jurkat.E6 cells suspended in CSB for $1 \mathrm{~h}$ in a final volume of $400 \mu \mathrm{L}$. After $1 \mathrm{~h}$, cells were washed with $9 \mathrm{~mL}$ of RPMI buffer to remove unbound DNA, and bound DNA was eluted in water by heating the mixture of cells and DNA for $10 \mathrm{~min}$ at $95{ }^{\circ} \mathrm{C}$. The collected supernatant was amplified with five polymerase chain reaction (PCR) cycles to expand the captured library, and the amplified library was converted to single-stranded DNA (ssDNA) using published protocols. Starting at round 2, a cycle optimization PCR was performed to determine the optimum number of PCR cycles for each round; expansion of the library was then performed accordingly to generate ssDNA. The process was repeated until the SELEX library was enriched with survivors. To increase the stringency of the selection, the number of cells utilized in SELEX was gradually decreased. The second round of SELEX was performed with $7 \times 10^{6}$ cells, and $4.5 \times 10^{6}$ cells were used in the third round. Then, $1.5 \times$ $10^{6}$ cells were utilized in subsequent rounds. The washes were increased to two $3 \mathrm{~mL}$ washes for rounds 2 to 4 and then increased to three washes starting at round 5 of SELEX until the final selection at round 10. Hot Start TaKaRa Taq DNA polymerase (5 units $/ \mu \mathrm{L}$, Clontech, catalog no. R007B) was used for AEGIS-SELEX during rounds 1-7, and all PCRs were carried out in 1× ThermoPol Reaction Buffer [20 mM Tris-HCl, $10 \mathrm{mM}$ $\left(\mathrm{NH}_{4}\right)_{2} \mathrm{SO}_{4}, 10 \mathrm{mM} \mathrm{KCl}, 2 \mathrm{mM} \mathrm{MgSO}_{4}$, and $0.1 \%$ Triton X-100 (pH 8.0) at $\left.25^{\circ} \mathrm{C}\right]$. 
Subsequent rounds were performed using Hot Start AmpliTaq Gold DNA polymerase (5 units $/ \mu \mathrm{L}$, Applied Biosystems, catalog no. 4311806) in 1× AmpliTaq Gold reaction buffer [15 mM Tris- $\mathrm{HCl}, 50 \mathrm{mM} \mathrm{KCl}$, and $2 \mathrm{mM} \mathrm{MgCl}_{2}$ (pH 8.0) at $25^{\circ} \mathrm{C}$ ].

Selection progress was monitored at rounds 7,9 , and 10 by incubating $0.2 \times 10^{6}$ Jurkat cells with Cy3-labeled ssDNA of the unselected control library and the selected library at a final concentration of $250 \mathrm{nM}$ in a total volume of $25 \mu \mathrm{L}$. After being incubated at $37^{\circ} \mathrm{C}$ for $1 \mathrm{~h}$, cells were washed once using $1 \mathrm{~mL}$ of RPMI medium and reconstituted in $200 \mu \mathrm{L}$ of RPMI. Binding events were analyzed using flow cytometry (BD FACScan).

\section{Determination of the Dissociation Constant of the Evolved SELEX Pool.}

Before LIGS was performed against Jurkat cells, the dissociation constant of the library was determined utilizing evolved 10th-round AEGIS-cell SELEX. To generate affinity curves, $250,125,50,25,10$, and $2 \mathrm{nM}$ concentrations of the 10th round, or the unselected control library, were used. To determine the affinity constant of the evolved pool, cells were first washed, and then a $20 \mu \mathrm{L}$ library was incubated with $20 \mu \mathrm{L}$ of $0.1 \times 10^{6}$ Jurkat cells for $1 \mathrm{~h}$ with gentle shaking at $37{ }^{\circ} \mathrm{C}$. After being incubated, cells were centrifuged at $5000 \mathrm{RCF}$ for $1 \mathrm{~min}$, and $35 \mu \mathrm{L}$ of the supernatant was removed. The cells were then reconstituted in 200 $\mu \mathrm{L}$ of RPMI and transferred into FACS tubes, followed by binding analysis by flow cytometry.

\section{Ligand-Guided Selection.}

LIGS was performed by adding $5 \mu \mathrm{L}$ of respective monoclonal antibodies and $25 \mu \mathrm{L}$ of the 10th-round ssDNA library to $20 \mu \mathrm{L}$ of $0.1 \times 10^{6}$ Jurkat cells suspended in CSB, and competitive binding was allowed by incubation for $1 \mathrm{~h}$ with gentle shaking. The final concentration of the 10th-round ssDNA library was kept at $50 \mathrm{nM}$, and the final $\mathrm{mAb}$ concentration was $30 \mathrm{nM}$ for each monoclonal antibody. After incubation for $1 \mathrm{~h}$, the supernatant containing competitively eluted sequences was collected, kept on crushed ice, and immediately amplified via PCR for NGS preparation.

\section{Preparation of Samples for Next-Generation Sequencing.}

Eluted molecules in LIGS and enriched cell-SELEX libraries were prepared for Illumina sequencing using a two-step PCR approach in which Illumina's overhang adapter sequences were obtained from Illumina's 16S metagenomic sequencing protocol. Two forward amplicon primers were designed by adding the SELEX forward primer sequence (underlined) and two different 10-base barcode sequences (shown in italics) into Illumina forward overhang adapter sequence. Ten-base barcodes were used for necessary conversion of $\mathrm{Z}$ and $\mathrm{P}$ nucleotides for sequencing. The reverse amplicon primer contained only the Illumina reverse overhang adapter sequence and the reverse primer used for SELEX. All the amplicon primers were purchased from IDT DNA Technologies: forward amplicon_A, 5' TCGTCGGCAGCGTCAGATGTGTATAAGAGACAGGATGATTGCCATAGACTGGACT GTCGTC-3' ; forward amplicon_B, $5^{\prime}$ TCGTCGGCAGCGTCAGATGTGTATAAGAGACAGCTTACACCACATAGACTGGACTG TCGTC-3'; reverse amplicon, $5^{\prime}$ GTCTCGTGGGCTCGGAGATGTGTATAAGAGACAGGACCTGTATCCGATGCTA-3' . 
The amplicon PCR was performed using seven PCR cycles, and the PCR product was purified using magnetic beads (Agencourt AMPure XP). Illumina sequencing adapters and indices for multiplexing were added by performing a second PCR using the Nextera XT Index Kit (FC-131-1001) using seven PCR cycles according to the conversion PCR protocol as previously described. $7,25,26$

The PCR product was purified and characterized by agarose gel electrophoresis. All samples were submitted to the Genomics and Epigenomics Core Facility at Weill-Cornell Medicine to perform Illumina sequencing. Sequencing of samples was done by further characterizing the product using Bioanalyzer (Agilent 2100 BioanalyzerSystem). Eight samples were pooled and sequenced by the Illumina HiSeq4000 instrument using singleread clustering and 100 cycles.

\section{Bioinformatics Analysis.}

To analyze the Illumina HT sequencing reads, the first step was to find "perfect" sequences, with perfect being defined as having the correct library size (35) along with a perfect match to each primer binding site and the barcodes. Reads that were not "perfect" were removed. The remaining reads were then clustered using a stepwise clustering algorithm that iteratively adds sequences with single-base changes and focuses solely on the library region, ignoring the differences in barcodes. As a secondary filter for initial library bases, any read that could be clustered using this algorithm with clusters found in the R0 library was also removed before attempting to cluster downstream rounds.

To find AEGIS base sites, these clusters were then separated by barcodes, and the base counts at each position in the library region were analyzed for patterns consistent with conversion from AEGIS bases. The clustered sequences obtained under the first conversion conditions (barcode $\mathrm{A}, \mathrm{Z}$ primarily to $\mathrm{C}$ and $\mathrm{P}$ primarily to $\mathrm{G}$ conversion) served as references for the clustered sequences obtained under the second conversion conditions (barcode $\mathrm{B}, \mathrm{Z}$ to $\mathrm{T} / \mathrm{A}$ and $\mathrm{P}$ to $\mathrm{C} / \mathrm{G}$ conversion). Sites where $\mathrm{C}$ and $\mathrm{T}$ were found in approximately equal amounts after conversion under the second set of conditions were assigned as Z in their "parent". Sites where G and A were found in approximately equal amounts after conversion under the second conditions were assigned as P in their "parent".

Sequences from data sets CD28, UCHT1, and OKT3 obtained from the FASTAptamerEnrich tool were used in the analysis. To establish a cutoff value, data from the enrichment fold $(\mathrm{Z} / \mathrm{Y})$, in which $\mathrm{Z}$ represents reads per million (RPM) data from sequences eluted using anti-human CD3 antibodies and Y represents RPM data from sequences eluted using the isotype, were plotted as a function of RPM (Z). From the plot, a value of 2 zenrichment fold $(\mathrm{Z} / \mathrm{Y})$ was designated as a cutoff value for UCHT1 and OKT3 sequences while a value of 1 zenrichment fold (Z/Y) was used to filter CD28 sequences (Galaxy Tool ID: Filter1). Note that the cutoff value for the CD28 sequence was different to ensure the removal of nonspecific binders. Lastly, sequences appearing in the CD28 data set were removed from the data set of UCHT1 and OKT3 sequences, retaining only the sequences binding to the CD3 receptor (Galaxy Tool ID: comp1). 
The resulting sequences were again filtered by setting up a cutoff value for RPM (X), which corresponds to the repeats of sequences appearing on R10 selection. Values, such as RPM (X) $\geq 1$, RPM (X) $\geq 0.5$, and RPM $\geq 0.25$, were used as other filtering parameters for the resulting sequences. In the end, a value of RPM $\geq 0.5$ was used as it provided the highest number of possible aptamer candidates with desirable characteristics. These candidates were then located within their parent cluster to find sites that had likely $\mathrm{Z}$ or $\mathrm{P}$ prior to conversion to natural bases, and these sites were used to make the AEGIS candidate aptamers.

\section{Aptamer Screening and Specificity Analysis.}

Following synthesis, initial screening of the binding toward the CD3 receptor of the 20 aptamer candidates was done using Jurkat cells (ATCC) as the positive cell line. First, synthesized sequences were resuspended in appropriate volumes of RPMI-1640 without HEPES to make a $100 \mu \mathrm{M}$ stock solution, and then dilution was performed to make a $1.0 \mu \mathrm{M}$ working solution for each binding assay. Sequences were unfolded by heating at $95^{\circ} \mathrm{C}$ for $10 \mathrm{~min}$, followed by centrifugation at $15000 \mathrm{rpm}$ and $4{ }^{\circ} \mathrm{C}$ for $30 \mathrm{~s}$. After the denaturation process, aptamer sequences were folded at $37^{\circ} \mathrm{C}$ for $1 \mathrm{~h}$. Briefly, Jurkat cells were washed with $3.0 \mathrm{~mL}$ of RPMI-1640 without HEPES three times, followed by resuspension with cell suspension buffer to yield a density of $1.0 \times 10^{5}$ cells per $100 \mu \mathrm{L}$ of solution. Cells were then incubated with $100 \mu \mathrm{L}$ of a $1 \mu \mathrm{M}$ aptamer solution and random control at $37^{\circ} \mathrm{C}$ for $1 \mathrm{~h}$. At the end of the incubation, cells were washed with 1.5 and $1 \mathrm{~mL}$ of washing buffer kept at $37^{\circ} \mathrm{C}$. The resulting cell pellets were then reconstituted in $300 \mu \mathrm{L}$ and analyzed via flow cytometry by counting 5000 events. Aptamer candidates that exhibited $>30 \%$ binding compared to random were further tested for their specificity using Toledo cells (ATCC) as the negative cell line.

\section{Target Specificity of the JZPO-10 Aptamer.}

To further test the specificity of the JZPO-10 aptamer toward the CD3 receptor, three trials of binding assays were performed using Jurkat cells (T-lymphocyte) as the positive cell line and Toledo (non-Hodgkin's B cell lymphoma) and MOLT-3 (T lymphoblast) cells as negative cell lines. It is noteworthy that negative cell lines are distinct from Jurkat cells as they do not express surface CD3 receptors. Herein, a $1.0 \mu \mathrm{M}$ working solution of JZPO-10 and random control was heated at $95^{\circ} \mathrm{C}$ for $10 \mathrm{~min}$, followed by centrifugation at $4{ }^{\circ} \mathrm{C}$ for $30 \mathrm{~s}$ and folding at $37^{\circ} \mathrm{C}$ for $1 \mathrm{~h}$. Afterward, cells were washed three times with $3.0 \mathrm{~mL}$ of RPMI-1640 without HEPES and resuspended with an appropriate volume of cell suspension buffer to make a suspension of $1.0 \times 10^{5}$ cells per $100 \mu \mathrm{L}$. Incubation was then performed by mixing $100 \mu \mathrm{L}$ of cells with $100 \mu \mathrm{L}$ of $1.0 \mu \mathrm{M}$ random or JZPO-10 and keeping the mixture at $37^{\circ} \mathrm{C}$ for $1 \mathrm{~h}$ without shaking. After incubation, cells were washed twice with 1.5 and 1.0 $\mathrm{mL}$ of RPMI-1640 buffer and reconstituted in $300 \mu \mathrm{L}$ of the same washing buffer. Binding was analyzed by running the cells under the flow cytometer using the parameter set to 5000 events. Median fluorescence data gathered from the flow cytometer were then used to determine the binding percentage using the formula $\left(\frac{\text { aptamer-random }}{\text { random }}\right) \times 100$. A bar graph was generated by further processing of binding percentage data using GraphPad Prism software. 
Affinity.

Analysis of the affinity of JZPO-10 and the truncated variants was performed by incubating $3.0 \times 10^{5}$ Jurkat.E6 cells with a range of aptamer concentrations $(2-250 \mathrm{nM})$ at $37{ }^{\circ} \mathrm{C}$ for 1

h. Cells were then washed once using $3 \mathrm{~mL}$ of RPMI-1640 buffer, and binding events were analyzed by flow cytometry. The specific median fluorescence intensity values were obtained by subtracting the fluorescence obtained from random DNA at each concentration from that of the aptamer (aptamer fluorescence intensity - random DNA fluorescence intensity). These values were then fitted on GraphPad Prism software to determine apparent affinity constants.

\section{Specificity Assay with Wild-Type and CRISPR-Cas9 Knockout Jurkat Cells at $37^{\circ} \mathrm{C}$.}

To evaluate the target specificity of JZPO10 against CD3/TCR, a specificity assay was conducted using Synthego's wild-type and Synthego's CRISPR-Cas9 knockout Jurkat cells. A $1 \mu \mathrm{M}$ working solution of JZPO10 and a random control were prepared by diluting the respective $10 \mu \mathrm{M}$ solution using RPMI. The working solutions were heated at $95^{\circ} \mathrm{C}$ for 10 min, followed by folding at $37^{\circ} \mathrm{C}$ for $1 \mathrm{~h}$. This assay was performed by incubating $75 \mu \mathrm{L}$ of a $1 \mu \mathrm{M}$ working solution of JZPO10, -10.3 , and -10.4 or a random control with $2.0 \times 10^{5}$ wild-type and knockout cells in $75 \mu \mathrm{L}$ of cell suspension buffer separately at $37^{\circ} \mathrm{C}$ for $1 \mathrm{~h}$. The incubation period was followed by washing twice with 1.5 and $1.0 \mathrm{~mL}$ of RPMI. Cells were reconstituted in $250 \mu \mathrm{L}$ of RPMI. Aptamer binding was analyzed by using FACSCalibur flow cytometry (Cytek Biosciences) by counting 5000 events. The percent of specific binding was determined as $\left(\frac{\text { aptamer-random }}{\text { random }}\right) \times 100$ and quantified using GraphPad Prism software. Reagents used for this experiment were kept at $37^{\circ} \mathrm{C}$.

\section{Competitive Binding Assays.}

Competitive binding assays in the presence of OKT3 mAb and anti-CD28 mAb as a control were conducted using the highest-affinity variant, JPO10.4 aptamer, at a final concentration of $40 \mathrm{nM}$. This was performed by adding $5 \mu \mathrm{L}$ of each mAb and $50 \mu \mathrm{L}$ of the JZPO10.4 aptamer to $45 \mu \mathrm{L}$ of $0.15 \times 10^{6}$ Jurkat cells in CSB and by incubating for $1 \mathrm{~h}$ at $37^{\circ} \mathrm{C}$. Here, an excess $\mathrm{mAb}$ concentration of $166 \mathrm{nM}$ was employed. After being incubated for $1 \mathrm{~h}$, the cells were centrifuged for $1 \mathrm{~min}$ at $5000 \mathrm{RCF}$ and reconstituted in $250 \mu \mathrm{L}$ of RPMI after the supernatant had been removed, and binding events were analyzed by flow cytometry. The percent of specific binding based on median fluorescence intensity was determined as $\left(\frac{\text { aptamer-random }}{\text { random }}\right) \times 100$. Three independent experiments were performed, and the results were analyzed using GraphPad Prism software by performing an unpaired $t$ test.

\section{RESULTS AND DISCUSSION}

\section{AEGIS-LIVE against Jurkat.E6 Cells.}

An AEGIS DNA library containing 35 randomized GACTZP nucleotides flanked by two 18base primers was synthesized with solid-phase synthesis using G/A/C/T/Z/P phosphoramidites in a 1/1/1/1/1/2 ratio. ${ }^{25}$ The PCR conditions were optimized against the PAGE-purified AEGIS DNA library to ensure efficient PCR amplification before LIVE 
against CD3-TCR-positive Jurkat.E6 cells. Furthermore, the expression of TCR-CD3 was validated using specific monoclonal antibodies (mAbs) UCHT1 and OKT3 to ensure that TCR-CD3 was sufficiently expressed on the cell surface (Figure S1). The AEGIS-LIVELIGS used in this study is shown in Scheme 1.

LIVE was begun by first folding the AEGIS DNA library by heating at $95^{\circ} \mathrm{C}$ for $10 \mathrm{~min}$ and cooling at $37^{\circ} \mathrm{C}$ for $1 \mathrm{~h}$. The first round of AEGIS-LIVE was performed by incubating 10 nmol of the folded library in RPMI1640, which is a physiologically relevant buffer used in cell culture, with 10 million Jurkat.E6 cells for $1 \mathrm{~h}$. Then the unbound molecules were washed with wash buffer, and winning AEGIS DNA ligands were recovered, followed by PCR amplification, utilizing a six-letter PCR mix with Hot Start Taq DNA polymerase, as reported previously. ${ }^{26}$ The PCR-amplified double-stranded library was then converted to ssDNA using established protocols. ${ }^{25}$ The selection pressure during LIVE was gradually increased in subsequent rounds by decreasing the number of cells while increasing the number of washes to eliminate weak binders. The progress of the selection was monitored during the seventh, ninth, and tenth rounds of Cy3-labeled AEGIS-LIVE pools using flow cytometry to measure the total binding of AEGIS-LIVE pools with Jurkat.E6 cells (Figure 1A). The seventh round of the AEGIS-LIVE pool did not show binding to Jurkat cells, suggesting a low level of enrichment of unique sequences; however, the ninth round of the AEGIS-LIVE pool bound to Jurkat.E6 cells (Figure 1A) and the tenth round of the AEGISLIVE pool continued to bind to Jurkat.E6 cells. The high median fluorescence observed for the ninth and tenth rounds of AEGIS-LIVE pools suggests enrichment of unique sequences toward the Jurkat.E6 cells. The shift on the $x$-axis observed for the tenth-round pool of AEGIS-LIVE, compared to the zero-round AEGIS-DNA pool, is similar to that of the thirteenth round in a separate LIVE experiment against the same cells using a natural DNA pool. ${ }^{19}$ Therefore, during the tenth round, AEGIS-LIVE was stopped. Additionally, pools from rounds 5,8 , and 10 were converted to the four-letter alphabet for Illumina-HT sequencing to calculate the enrichment of unique sequences (Figure 3A). The conversion of AGCTZP to AGCT was performed using a previously described protocol during the second PCR that employed attachment of Illumina indices and sequencing adapters. ${ }^{26}$

\section{AEGIS-LIGS.}

The LIGS method has been developed to exploit the differences in the dissociation constants of individual aptamers in an enriched LIVE pool. ${ }^{3,17-19}$ Because of the combinatorial nature of a LIVE pool, at any given concentration, the individual AEGIS DNA aptamer is present at substantially low concentrations. ${ }^{3,17-19}$ Because LIGS is rooted in the concentrations of the enriched LIVE pools and that of the competing ligands, we first determined the affinity of the enriched tenth round of the AEGIS-LIVE pool against Jurkat.E6 cells (Figure 2A). The calculated apparent dissociation constant of the tenth round of the AEGIS-LIVE pool against Jurkat.E6 cells was $174 \pm 79 \mathrm{nM}$ (Figure $2 \mathrm{~A}$ ). The affinity constants of the competing mAbs used in LIGS were calculated as $1.5 \pm 0.3 \mathrm{nM}$ for OKT3 and $1.4 \pm 0.3 \mathrm{nM}$ for UCHT1. The affinity of the control mAb anti-CD28 was $1.6 \pm 0.2 \mathrm{nM}$. Four types of $\mathrm{mAbs}$ were used in LIGS. First, an isotype control was used to identify high off-rate weak binders. Second, two mAbs against $\mathrm{CD} 3 \varepsilon$ (clones OKT3 and UCHT1) were used to elute AEGIS ligands enriched against TCR-CD3 $\varepsilon$ in Jurkat.E6 cells specifically. Third, a control 
$\mathrm{mAb}$ (anti-CD28) was used to identify nonspecifically eluted sequences resulting from an antibody-antigen interaction, which might have eluted off-target sequences. On the basis of our previous studies, we found that these off-target sequences contaminate LIGS pools and complicate identification of specific hits during bioinformatics analysis. Each mAb was used at concentrations that were 20 -fold greater than their respective dissociation constant. The mAbguided elution was allowed for $1 \mathrm{~h}$ at $37^{\circ} \mathrm{C}$. After $1 \mathrm{~h}$, the supernatant containing eluted sequences was collected and amplified via PCR for Illumina-HT sequencing.

Binding of the tenth round of the AEGIS-LIVE pool with Jurkat.E6 cells after adding mAb was evaluated by flow cytometry. A reduction in the total level of binding of the tenth-round AEGIS-LIVE pool with Jurkat.E6 cells in the presence of anti-CD3 mAbs (OKT3 and UCHT1) compared to the isotype control antibody was observed (Figure 2B,C). Comparison of the median fluorescence of tenth-round AEGIS-LIVE pool binding against Jurkat.E6 cells with tenth-round AEGIS-LIVE pool binding after adding OKT3 and UCHT1 showed a $43 \%$ reduction in the level of binding of the tenth round. On the other hand, no significant reduction in the level of tenth-round AEGIS-LIVE pool binding with Jurkat cells was observed when the anti-CD28 antibody was added, suggesting specific elution of AEGIS ligands in the presence of OKT3 and UCHT1. The supernatants from all LIGS conditions were collected and prepared for Illumina-HT sequencing. Illumina-HT DNA sequencing samples are listed in Table S1.

\section{Bioinformatics Analysis of AEGIS-LIVE-LIGS Pools.}

Preprocessed sequencing data were first analyzed using the FASTAptamer toolkit. ${ }^{4}$ First, the FASTAptamer-Count command was used to order sequences based on their abundance. Second, using the same command, the normalized read counts (RPM) of the unique sequences were identified. To elucidate the progress of LIVE and the nature of unique sequences eluted by specific mAbs during LIGS, the enrichment of unique sequences in the fifth-, eighth-, and tenth-round pools of AEGIS-LIVE was evaluated.

To do this, the enrichment was defined as $\left(1-\frac{\text { number of unique sequences }}{\text { total number of sequences }}\right) \times 100 .{ }^{27}$ As LIVE progresses, the enrichment of unique sequences in a LIVE pool increases, while the diversity of the pool decreases. The enrichment of the fifth-round AEGIS-LIVE pool is at approximately $10 \%$, and this value gradually increased to $30 \%$ at the tenth round of AEGISLIVE. Interestingly, the evaluation of enrichment of unique sequences eluted by specific mAbs is approximately $45 \%$, suggesting higher enrichment of unique sequences in LIGS pools (Figure 3A). Third, the FASTAptamer-Enrich tool was used to calculate fold enrichment ratios of individual sequences present in the tenth round of AEGIS-LIVE pools and LIGS pools. This was done by defining inputs as $\mathrm{X}=$ the total number of AEGIS DNA sequences enriched in round $10, \mathrm{Y}=$ the number of sequences that appeared in the supernatant of the isotype control, and $\mathrm{Z}=$ the number of specific sequences eluted by specific $\mathrm{mAbs}$, i.e., OKT3, UCHT1, and anti-CD28 in LIGS. The parameter Z corresponding to three different mAbs utilized during LIGS led to three tabular FASTAptamer-Enrich files corresponding to each mAb. Fourth, the generated FASTAptamer-Enrich files from the third step were further analyzed using the GALAXY platform as described before. Briefly, GALAXY analysis involved plotting the total abundance (RPM) 
of sequences identified in the supernatant corresponding to each $\mathrm{mAb}$ as a function of fold enrichment for each mAb/isotype (Z/Y) (Figure 3B-D). This step was performed to evaluate the abundance of specifically eluted ligands by each mAb utilized in LIGS (Figure 3B-D). Then, a cutoff criterion of $\geq 2$ for fold enrichment was defined on the basis of the distribution of the sequences observed for each plot. Fifth, we followed a subtraction strategy similar to that reported recently by our group to remove potential nonspecific sequences. To do this, the sequences with a fold enrichment value of $\geq 1$ in the sequencing data that originated from the control mAb (anti-CD28) were first removed. This step was done to remove any sequence potentially eluted as a result of interaction between $\mathrm{mAb}$ and antigen on the cell, rather than a true competition. Sixth, the sequences not appearing during the tenth round of AEGIS-LIVE pool, but appearing in LIGS pools, were filtered to remove sequences that originated from sequencing, or PCR errors. After steps 1-6, 853 sequences were identified for the OKT3 mAb and 1226 sequences for the UCHT1 mAb. Seventh and last, we removed any sequence with RPM values of $<0.5$ in the tenth round of AEGIS-LIVE pools to remove hits that originated from sequencing and PCR errors. After this step, a total of 36 unique sequences were identified as being specifically eluted by OKT3 and UCHT1. Interestingly, four of the 30 sequences appeared in both OKT3 and UCHT1 pools. Of a total of 30, 12 sequences could not be converted to their GATCZP analogues because of low read counts. The conversion strategy described in the bioinformatics analysis in Materials and Methods allows conversion of only the highly abundant sequences, not sequences with low abundance, which might have affected the identification of potential hits. The remaining sequences were converted to AEGIS hit sequences using sequence clusters as described previously. ${ }^{7,26}$ The 14 sequences with read counts of $>1000$ were chemically synthesized and tested for specificity (Table 1).

\section{Identification of Aptamers.}

All 14 AEGIS aptamer candidates were screened for cell specificity using CD3-positive Jurkat.E6 cells. Two negative control cells with no TCR-CD3 expression, MOLT-3 and Toledo cells, were used as the negative control. We defined positive binding as $>30 \%$ of $\left(\frac{\text { aptamer-random }}{\text { random }}\right) \times 100$. Of a total of 20 candidates tested, one aptamer candidate, termed JZPO-10, showed consistent specific binding against Jurkat.E6 cells (Figure 4A,B and Figures S2 and S3 for binding analyses of all 14 aptamers and Figure S4 for analysis of antiCD3 mAb binding). The specificity of the JZPO-10 aptamer was further investigated using a CD3/TCR double-knockout Jurkat cell line generated by CRISPR-Cas9. The AEGIS ligand JZPO-10 showed specific binding to wild-type Jurkat cells (Figure 4C, left) but not toward the CRISPR-Cas9 knockout cells with no CD3/TCR expression (Figure 4C, right), confirming the epitope specificity of the JZPO-10 aptamer against the CD3/TCR receptor complex.

The affinity of the JZPO-10 aptamer was evaluated as $44 \pm 21 \mathrm{nM}$ using CD3-positive Jurkat.E6 cells (Figure 4D). We and others have shown that the systematic truncation of aptamers can lead to higher affinity by increasing the population of the functional fold. ${ }^{28-30}$ Thus, systematic truncations on the JZPO-10 aptamer were performed to increase its affinity (Table 2). The variant JZPO-10.1 that resulted from removing six bases from the $5^{\prime}$ and $3^{\prime}$ constant regions showed a slightly lower affinity of $81 \pm 29 \mathrm{nM}$. The second variant, 
JZPO-10.3, was generated by removing six more bases from the $5^{\prime}$ constant region, and it showed an affinity of $57 \pm 23 \mathrm{nM}$. The third variant generated from removing bases from the $3^{\prime}$ constant region (JZPO-10.4) showed a slightly improved affinity of $34 \pm 9 \mathrm{nM}$ (see Figure S5 for affinity curves). Truncation analysis suggests that nucleotides at the $5^{\prime}$ constant region may play a role in stabilizing the functional fold of JZPO-10. The target specificity of the truncated aptamers JZPO-10.3 and JZPO-10.4 was further analyzed using two control cell lines. Both aptamers showed binding against wild-type Jurkat cells but not against the CD3/TCR knockout Jurkat or MOLT-3 cells, suggesting that the truncations did not compromise specificity (Figure 5A). The competitive binding experiments in the presence of the OKT3 antibody were performed to further validate the epitope specificity of the aptamers. Thus, the binding of the highest-affinity variant, JZPO-10.4, with Jurkat.E6 cells was analyzed in the presence of the OKT3 mAb using the anti-CD28 mAb as the control (Figure S6 shows histograms of mAb binding). A significant reduction in the level of binding of the JZPO-10.4 aptamer with target Jurkat cells was observed in the presence of the OKT3 mAb compared to anti-CD28 (Figure 5B,C), suggesting that the aptamer binds to the same, or an overlapping, epitope of the OKT3 antibody.

Here, we show, for the first time, an example of selecting an AEGIS-based DNA ligand against TCR-CD $3 \varepsilon$ using LIGS. The combination of AEGIS and LIGS is vital in several respects. First, cell-surface proteins are attractive cellular targets in drug discovery, diagnosis, and modulation of cell-cell interactions. ${ }^{31}$ However, cell-surface proteins have proven to be complex targets. ${ }^{3}$ Thus far, ligand discovery against purified cell-surface proteins has been predominately ineffective. The establishment of LIGS addressed this challenge and successfully identified functional ligands without changing the cell-surface protein's native functional state. Second, nucleic acid ligands composed of natural GACT lack structural diversity, which often leads to either lower-affinity aptamers or requires a higher number of selection rounds. Introduction of AEGIS DNA pools combined with LIVE addressed the issue of diversity to effectively identify AEGIS DNA aptamers. Here, we introduce a superior screening strategy combining two critical advantages of AEGIS and LIGS to discover artificial nucleic ligands against a cell-surface target. The utility of AEGIS in discovering artificial ligands against cell-surface proteins shows great promise. The recent trend in this regard is to maximize ligand binding capacity by enhancing the structural diversity of natural nucleic acids to mimic the binding properties of ligands that are protein counterparts. For example, the introduction of SOMAmers, with substantial hydrophobic modifications, shows that the level of selectivity and affinity can be achieved by modifying nucleic acid ligands. ${ }^{12}$ What is unique in AEGIS libraries is that the $\mathrm{Z}$ and $\mathrm{P}$ nucleotides used in LIVE are independently replicable. The final composition of the aptamers is truly based on the performance of LIVE and the effectiveness of PCR in accepting $\mathrm{Z}$ and P bases.

In evaluating the progress of selection, we utilized two approaches. These are traditional flow cytometric analysis to evaluate the binding of the fluorescently labeled enriched pools and sequencing of AEGIS-LIVE pools from three different rounds. Interestingly, our previous work with selecting natural GATC aptamers against TCR-CD3-positive Jurkat.E6 cells showed a shift at round 12 similar to that of round 10 of the AEGIS-LIVE pool. However, the enrichment of unique sequences was substantially different with $80 \%$ enrichment of the natural GACT library, compared to $30 \%$ enrichment observed for the 
AEGIS-LIVE library against the same cell. This suggests that greater diversity in the library leads to a higher number of ligands against a whole cell, even with $30 \%$ enrichment. The preprocessed sequences followed by downstream analysis showed 30 potential AEGIS hits.

Interestingly, analysis of the sequence composition of $\mathrm{Z}$ and $\mathrm{P}$ in the final survivor hits shows a stronger appearance of $\mathrm{P}$ in the random region but not $\mathrm{Z}$. This observation is comparable to the observation made by Bondi et al. when LIVE was performed using AEGIS against protective antigen $3 .{ }^{16}$ There are several reasons for the lack of $Z$ in the final hits. First, the DNA polymerase utilized in PCR prefers to amplify standard oligonucleotides $\mathrm{dA}, \mathrm{dC}, \mathrm{dG}$, and $\mathrm{dT}$ over nonstandard dZ- and dP-containing oligos; therefore, the survivors after several rounds of selection tend to have fewer nonstandard $\mathrm{dZ}$ and $\mathrm{dP}$ bases. Second, the nonstandard bases can be easily lost during PCR with low-fidelity polymerase. The challenge of successful six-letter PCR is to have a polymerase to faithfully replicate nonstandard bases, especially in SELEX involving more than 200 cycles of PCR. Third, either $\mathrm{P}$ is highly desirable in PCR amplification or in protein recognition, which leads to enrichment of sequences with a higher percentage of $\mathrm{P}$ but not $\mathrm{Z}$.

\title{
CONCLUSIONS
}

In conclusion, this proof of concept study, for the first time, demonstrates how combining molecular interactions with in vitro evolution utilizing AEGIS DNA libraries, Illumina-HT sequencing, and bioinformatics can result in the identification of highly specific nucleic acid ligands composed of AEGIS DNA against a multicomponent cell-surface receptor protein expressed on Jurkat.E6 cells. This study elucidates the simplicity of LIGS in expanding the repertoire of LIVE libraries that can be utilized in effective artificial ligand discovery. While the affinity of selected aptamers can vary with the degree of enrichment of the LIVE library or the efficiency of the conversion platform, the unprecedented specificity of JZPO-10 further confirms the utility of LIGS in generating artificial nucleic acid ligands against cellular targets. Because TCR-CD3 is an essential target in immune reactions, JZPO-10 could be utilized in the potential development of AEGIS DNA aptamer-based immunomodulators.

\section{Supplementary Material}

Refer to Web version on PubMed Central for supplementary material.

\section{ACKNOWLEDGMENTS}

\author{
The authors thank Kevin Bradely for converting the four-letter alphabet to the six-letter alphabet of Illumina-HT \\ data following Galaxy analysis and Chris McLendon for his efforts in the synthesis and purification of the six \\ aptamers. The content of this publication is solely the responsibility of the authors and does not necessarily \\ represent the official views of the National Institutes of Health. \\ Funding
}

The authors are grateful for funding for this work by National Institute of General Medical Sciences Grant SC1 GM122648. S.A.B. was supported by the National Institutes of Health under Director's Award R01GM128186. 


\section{REFERENCES}

(1). Ellington AD, and Szostak JW (1990) In vitro selection of RNA molecules that bind specific ligands. Nature 346, 818-822. [PubMed: 1697402]

(2). Tuerk C, and Gold L (1990) Systematic evolution of ligands by exponential enrichment: RNA ligands to bacteriophage T4 DNA polymerase. Science 249, 505-510. [PubMed: 2200121]

(3). Mallikaratchy P (2017) Evolution of Complex Target SELEX to Identify Aptamers against Mammalian Cell-Surface Antigens. Molecules 22, 215.

(4). Alam KK, Chang JL, and Burke DH (2015) FASTAptamer: A Bioinformatic Toolkit for Highthroughput Sequence Analysis of Combinatorial Selections. Mol. Ther.-Nucleic Acids 4, e230. [PubMed: 25734917]

(5). Fraser L, Liang S, Shiu S, and Tanner J (2017) Aptamer Bioinformatics. Int. J. Mol. Sci 18, 2516.

(6). Schutze T, Wilhelm B, Greiner N, Braun H, Peter F, Morl M, Erdmann VA, Lehrach H, Konthur Z, Menger M, Arndt PF, and Glokler J (2011) Probing the SELEX process with next-generation sequencing. PLoS One 6, e29604. [PubMed: 22242135]

(7). Sefah K, Yang Z, Bradley KM, Hoshika S, Jimenez E, Zhang L, Zhu G, Shanker S, Yu F, Turek D, Tan W, and Benner SA (2014) In vitro selection with artificial expanded genetic information systems. Proc. Natl. Acad. Sci. U. S. A 111, 1449-1454. [PubMed: 24379378]

(8). Biondi E, and Benner SA (2018) Artificially Expanded Genetic Information Systems for New Aptamer Technologies. Biomedicines 6, 53.

(9). Taylor AI, Houlihan G, and Holliger P (2019) Beyond DNA and RNA: The Expanding Toolbox of Synthetic Genetics. Cold Spring Harbor Perspect. Biol 11, a032490.

(10). Leconte AM, Hwang GT, Matsuda S, Capek P, Hari Y, and Romesberg FE (2008) Discovery, characterization, and optimization of an unnatural base pair for expansion of the genetic alphabet. J. Am. Chem. Soc 130, 2336-2343. [PubMed: 18217762]

(11). He W, Elizondo-Riojas MA, Li X, Lokesh GL, Somasunderam A, Thiviyanathan V, Volk DE, Durland RH, Englehardt J, Cavasotto CN, and Gorenstein DG (2012) X-aptamers: a bead-based selection method for random incorporation of druglike moieties onto next-generation aptamers for enhanced binding. Biochemistry 51, 8321-8323. [PubMed: 23057694]

(12). Gold L, Ayers D, Bertino J, Bock C, Bock A, Brody EN, Carter J, Dalby AB, Eaton BE, Fitzwater T, Flather D, Forbes A, Foreman T, Fowler C, Gawande B, Goss M, Gunn M, Gupta S, Halladay D, Heil J, Heilig J, Hicke B, Husar G, Janjic N, Jarvis T, Jennings S, Katilius E, Keeney TR, Kim N, Koch TH, Kraemer S, Kroiss L, Le N, Levine D, Lindsey W, Lollo B, Mayfield W, Mehan M, Mehler R, Nelson SK, Nelson M, Nieuwlandt D, Nikrad M, Ochsner U, Ostroff RM, Otis M, Parker T, Pietrasiewicz S, Resnicow DI, Rohloff J, Sanders G, Sattin S, Schneider D, Singer B, Stanton M, Sterkel A, Stewart A, Stratford S, Vaught JD, Vrkljan M, Walker JJ, Watrobka M, Waugh S, Weiss A, Wilcox SK, Wolfson A, Wolk SK, Zhang C, and Zichi D (2010) Aptamer-based multiplexed proteomic technology for biomarker discovery. PLoS One 5, e15004. [PubMed: 21165148]

(13). Kimoto M, Yamashige R, Matsunaga K, Yokoyama S, and Hirao I (2013) Generation of highaffinity DNA aptamers using an expanded genetic alphabet. Nat. Biotechnol 31, 453-457. [PubMed: 23563318]

(14). Benner SA, Karalkar NB, Hoshika S, Laos R, Shaw RW, Matsuura M, Fajardo D, and Moussatche P (2016) Alternative Watson-Crick Synthetic Genetic Systems. Cold Spring Harbor Perspect. Biol 8, a023770.

(15). Zhang L, Yang Z, Le Trinh T, Teng IT, Wang S, Bradley KM, Hoshika S, Wu Q, Cansiz S, Rowold DJ, McLendon C, Kim MS, Wu Y, Cui C, Liu Y, Hou W, Stewart K, Wan S, Liu C, Benner SA, and Tan W (2016) Aptamers against Cells Overexpressing Glypican 3 from Expanded Genetic Systems Combined with Cell Engineering and Laboratory Evolution. Angew. Chem., Int. Ed 55, 12372-12375.

(16). Biondi E, Lane JD, Das D, Dasgupta S, Piccirilli JA, Hoshika S, Bradley KM, Krantz BA, and Benner SA (2016) Laboratory evolution of artificially expanded DNA gives redesignable aptamers that target the toxic form of anthrax protective antigen. Nucleic Acids Res. 44, 95659577. [PubMed: 27701076] 
(17). Zumrut HE, Ara MN, Maio GE, Van NA, Batool S, and Mallikaratchy PR (2016) Ligand-guided selection of aptamers against T-cell Receptor-cluster of differentiation 3 (TCR-CD3) expressed on Jurkat.E6 cells. Anal. Biochem 512, 1-7. [PubMed: 27519622]

(18). Zumrut HE, Ara MN, Fraile M, Maio G, and Mallikaratchy P (2016) Ligand-Guided Selection of Target-Specific Aptamers: A Screening Technology for Identifying Specific Aptamers Against Cell-Surface Proteins. Nucleic Acid Ther. 26, 190-198. [PubMed: 27148897]

(19). Zumrut HE, Batool S, Argyropoulos KV, Williams N, Azad R, and Mallikaratchy PR (2019) Integrating Ligand-Receptor Interactions and In Vitro Evolution for Streamlined Discovery of Artificial Nucleic Acid Ligands. Mol. Ther--Nucleic Acids 17, 150-163. [PubMed: 31255977]

(20). Zumrut HE, Batool S, Van N, George S, Bhandari S, and Mallikaratchy P (2017) Structural optimization of an aptamer generated from Ligand-Guided Selection (LIGS) resulted in high affinity variant toward mIgM expressed on Burkitt's lymphoma cell lines. Biochim. Biophys. Acta, Gen. Subj 1861, 1825-1832. [PubMed: 28363693]

(21). Moccia F, Platella C, Musumeci D, Batool S, Zumrut H, Bradshaw J, Mallikaratchy P, and Montesarchio D (2019) The role of G-quadruplex structures of LIGS-generated aptamers R1.2 and R1.3 in IgM specific recognition. Int. J. Biol. Macromol 133, 839-849. [PubMed: 31022491]

(22). Batool S, Argyropoulos KV, Azad R, Okeoma P, Zumrut H, Bhandari S, Dekhang R, and Mallikaratchy PR (2019) Dimerization of an aptamer generated from Ligand-guided selection (LIGS) yields a high affinity scaffold against B-cells. Biochim. Biophys. Acta, Gen. Subj 1863, 232-240. [PubMed: 30342154]

(23). Arnett KL, Harrison SC, and Wiley DC (2004) Crystal structure of a human CD3-epsilon/delta dimer in complex with a UCHT1 single-chain antibody fragment. Proc. Natl. Acad. Sci. U. S. A 101, 16268-16273. [PubMed: 15534202]

(24). Kjer-Nielsen L, Dunstone MA, Kostenko L, Ely LK, Beddoe T, Mifsud NA, Purcell AW, Brooks AG, McCluskey J, and Rossjohn J (2004) Crystal structure of the human T cell receptor CD3 epsilon gamma heterodimer complexed to the therapeutic mAb OKT3. Proc. Natl. Acad. Sci. U. S. A 101, 7675-7680. [PubMed: 15136729]

(25). Zhang L, Yang Z, Sefah K, Bradley KM, Hoshika S, Kim MJ, Kim HJ, Zhu G, Jimenez E, Cansiz S, Teng IT, Champanhac C, McLendon C, Liu C, Zhang W, Gerloff DL, Huang Z, Tan W, and Benner SA (2015) Evolution of functional six-nucleotide DNA. J. Am. Chem. Soc 137, 67346737. [PubMed: 25966323]

(26). Yang Z, Durante M, Glushakova LG, Sharma N, Leal NA, Bradley KM, Chen F, and Benner SA (2013) Conversion strategy using an expanded genetic alphabet to assay nucleic acids. Anal. Chem 85, 4705-4712. [PubMed: 23541235]

(27). Thiel WH, and Giangrande PH (2016) Analyzing HT-SELEX data with the Galaxy Project toolsA web based bioinformatics platform for biomedical research. Methods 97, 3-10. [PubMed: 26481156]

(28). Zumrut HE, Batool S, Van N, George S, Bhandari S, and Mallikaratchy P (2017) Structural optimization of an aptamer generated from Ligand-Guided Selection (LIGS) resulted in high affinity variant toward mIgM expressed on Burkitt's lymphoma cell lines. Biochim. Biophys. Acta, Gen. Subj 1861, 1825-1832. [PubMed: 28363693]

(29). Mallikaratchy PR, Ruggiero A, Gardner JR, Kuryavyi V, Maguire WF, Heaney ML, McDevitt MR, Patel DJ, and Scheinberg DA (2011) A multivalent DNA aptamer specific for the B-cell receptor on human lymphoma and leukemia. Nucleic Acids Res. 39, 2458-2469. [PubMed: 21030439]

(30). Maio G, Enweronye O, Zumrut HE, Batool S, Van N, and Mallikaratchy P (2017) Systematic optimization and modification of a DNA aptamer with $2^{\prime}$-O-methyl RNA analogues. ChemistrySelect 2, 2335-2340. [PubMed: 29226219]

(31). Batool S, Bhandari S, George S, Okeoma P, Van N, Zumrut HE, and Mallikaratchy P (2017) Engineered Aptamers to Probe Molecular Interactions on the Cell Surface. Biomedicines 5, 54. 
A

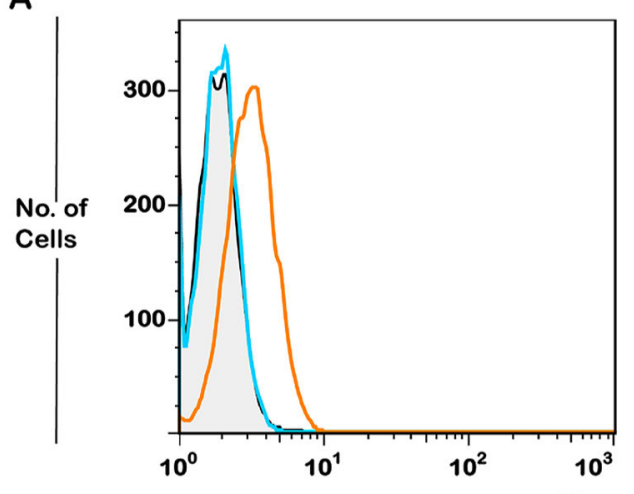

B

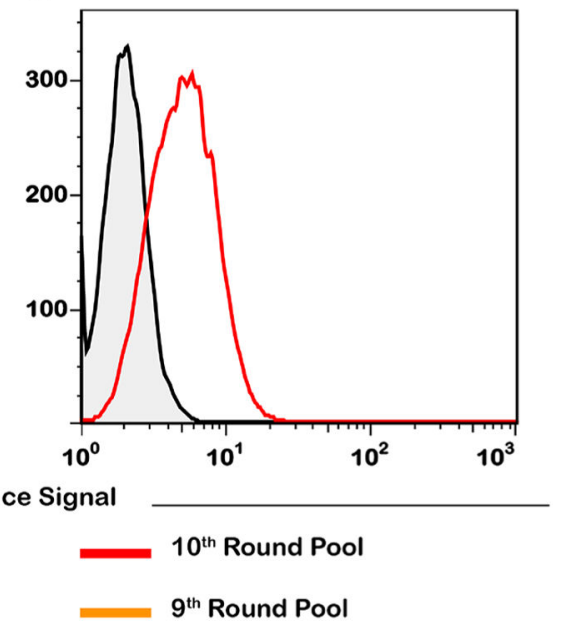

Figure 1.

Flow cytometric analysis of the progress of AEGIS-LIVE against Jurkat.E6 cells. (A) Flow cytometric analysis for the binding of the seventh (blue) and ninth (orange) rounds of AEGIS-LIVE pools. (B) Flow cytometric analysis of the tenth round of the AEGIS-LIVE pool. 
A

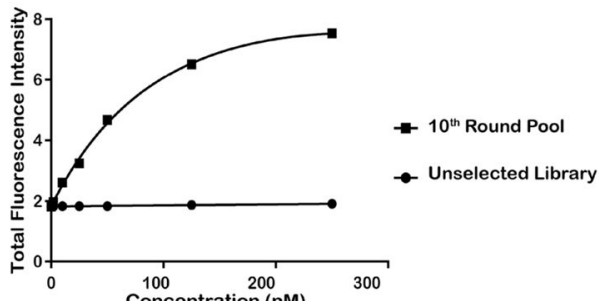

C

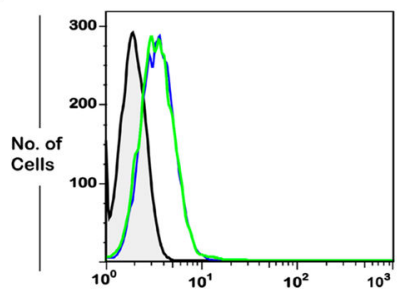

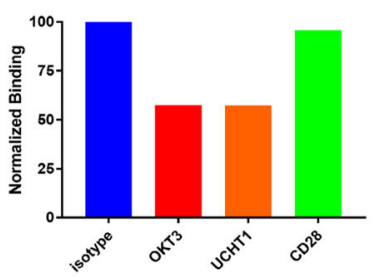
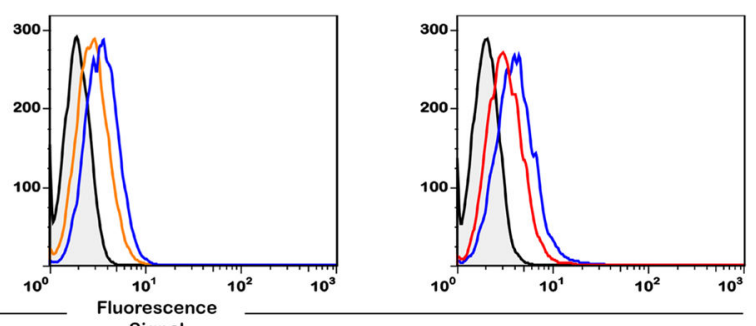

Signal

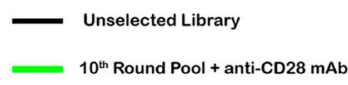

$10^{\text {th }}$ Round Pool + UCHT1 mAb

$10^{\text {th }}$ Round Pool + OKT3 mAb

Figure 2.

Post-LIGS analysis of tenth-round AEGIS-LIVE pool binding. (A) Analysis of tenth-round AEGIS-LIVE pool affinity with Jurkat.E6 cells. (B) Evaluation of tenth-round AEGISLIVE pool binding with Jurkat cells in the presence of an isotype control, anti-CD28, OKT3, and UCHT1. The normalized binding on the $y$-axis was obtained by first calculating specific binding values compared to the unselected control library as $\left(\frac{\text { fluorescence signal for round } 10-\text { fluorescence signal for control }}{\text { fluorescence for control }}\right) \times 100$. Specific binding was then normalized against the total binding obtained in the presence of the isotype control antibody. Then the binding values (median fluorescence intensity of respective histograms) corresponding to each antibody were normalized to total binding. (C) Post-LIGS analysis of tenth-round AEGIS-LIVE pool binding to Jurkat cells in the presence of the isotype control antibody (blue), the anti-CD28 antibody (green), the UCHT1 antibody (orange), or the OKT3 antibody (red). 


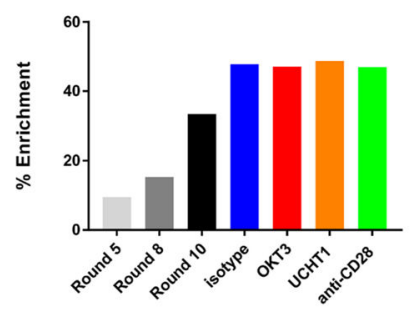

C

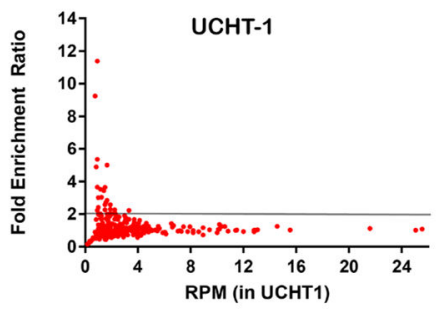

B

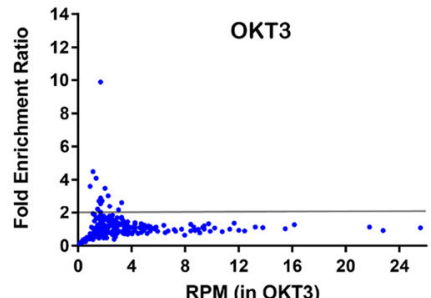

D

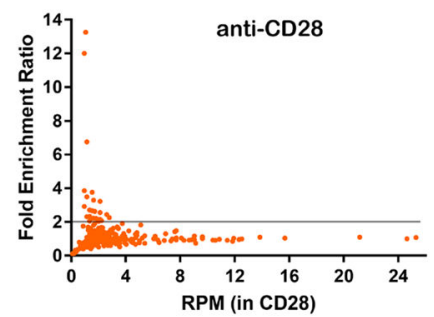

$\mathbf{E}$

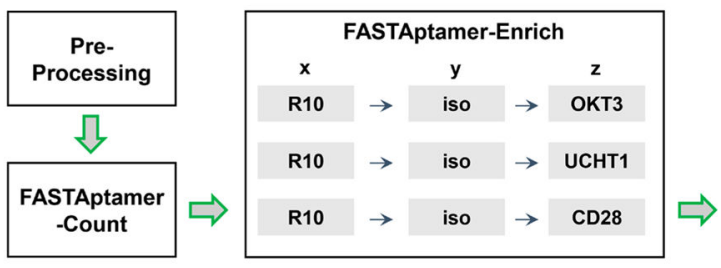

Description of Abbreviations $x, y$ and $z$ : refers to inputs for FASTAptamer-Enrich runs $x=$ FASTAptamer-Count data obtained from the sequencing of $10^{\text {th }}$ round AEGIS-cell SELEX library (R10)

$y=$ FASTAptamer-Count data obtained from the sequencing of supernatant when isotype control antibody (iso) was used during LIGS experiment.

$z=$ FASTAptamer-Count data obtained from the sequencing of supernatan when a specific monoclonal antibody (mAb) was used during LISS experiment.

Each FASTAptamer-Enrich run was performed using a different $m A b$ for the third input (z) : 1) $z=$ OKT3 mAb 2) $z=U C H T 1$ mAb 3) $z=$ anti-CD28 mAb.

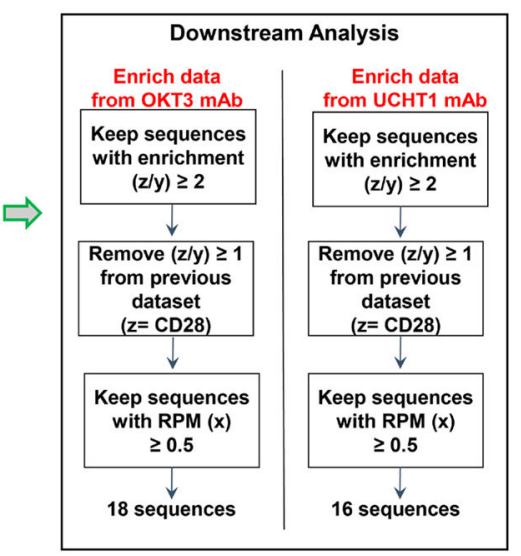

Figure 3.

Bioinformatics analysis of LIVE pools and LIGS pools to identify AEGIS DNA ligands. (A) Enrichment, as defined by $\left(1-\frac{\text { number of unique sequences }}{\text { total number of sequences }}\right) \times 100$, was calculated for AEGISLIVE pools from the fifth, eighth, and tenth rounds, and the enrichment was calculated for LIGS pools that originated from isotype, OKT3, UCHT1, and anti-CD20 mAbs. The fold enrichment ratios against isotype control antibody for the (B) OKT3, (C) UCHT1, and (D) anti-CD28 mAbs were plotted as a function of the normalized read counts (RPM) for individual sequences. Sequences showing a fold enrichment value of $>2$ (above the solid line) were considered as specific against each mAb. (E) Flowchart summarizing the GALAXY workflow sequence files for OKT3 and UCHT1 to identify specific hit AEGIS DNA ligand candidates. 
A

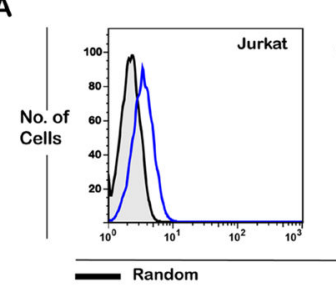

C

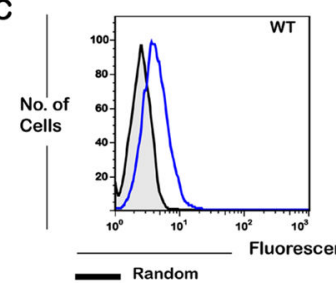

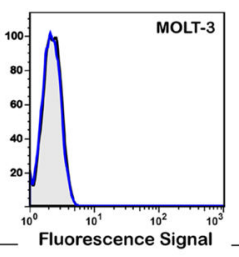

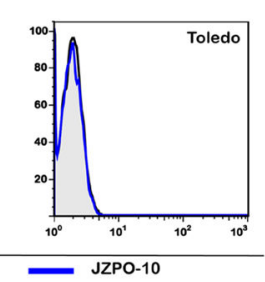

B

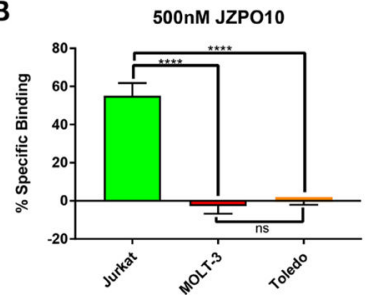

Figure 4.

Specificity analyses of the JZPO-10 aptamer. (A) Flow cytometric analyses for binding of the JZPO-10 aptamer against Jurkat.E6 (left), MOLT-3 (middle), and Toledo (right) cells. (B) Overall conclusion from three independent binding assays against each cell line. The percentage of specific binding on the $y$-axis for each cell line was determined as $\left(\frac{\text { aptamer-random }}{\text { random }}\right) \times 100$. Statistical analysis was performed in GraphPad Prism using one-way ANOVA and Tukey's multiple-comparison test $(* * * * p<0.0001)$. (C) Binding analysis of the JZPO-10 aptamer against wild-type Jurkat cells used for CRISPR-Cas9 (left) and against a CD3 $\varepsilon$ /TCR $a$ double-knockout Jurkat cell line generated by CRISPR-Cas9 (right) (Figure S3 shows antibody staining). (D) Overall conclusion from four independent binding analyses using wild-type and knockout Jurkat cells. The percentage of specific binding on the $y$-axis was calculated using the formula mentioned above. Statistical significance was evaluated by an unpaired $t$ test using GraphPad Prism $(* * * * p<0.0001)$.

Biochemistry. Author manuscript; available in PMC 2021 February 04. 

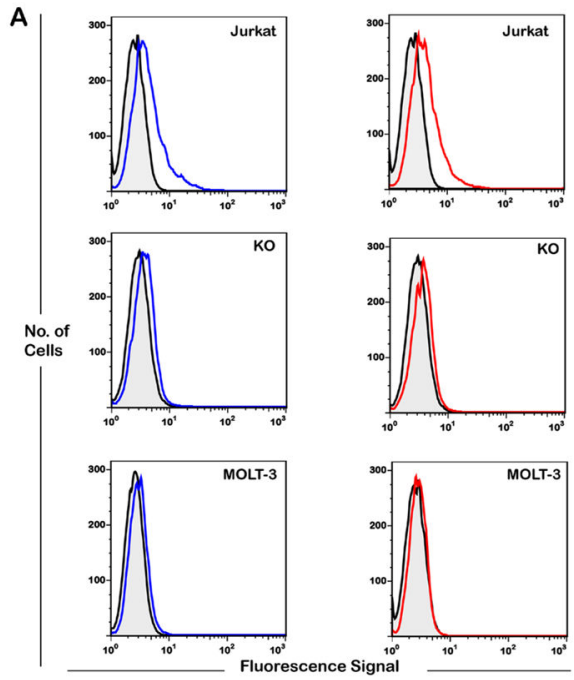

JZPO-10.3
Random

JZPO-10.4
Random
B
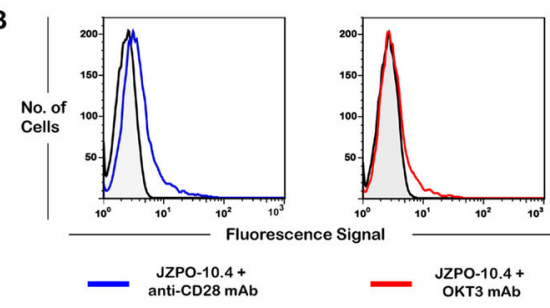

- $\begin{gathered}\text { Random + } \\ \text { anti-CD28 mAb }\end{gathered} \quad \begin{aligned} & \text { Random }+ \\ & \text { OKT3 mAb }\end{aligned}$

C

40nM JZPO10.4

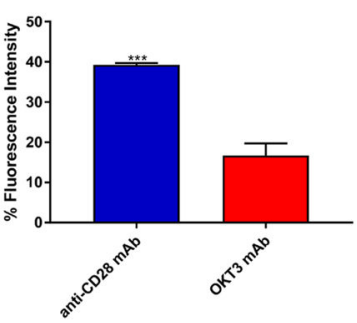

Figure 5.

Analyses of cellular and epitope specificity of two truncated variants of the JZPO-10 aptamer. (A) Binding analysis of JZPO-10.3 and JZPO-10.4 aptamers against wild-type Jurkat (top), CD3 $\varepsilon$ /TCR $a$ double-knockout Jurkat (middle), and MOLT-3 (bottom) cells. (B) Flow cytometric analyses of competitive binding experiments of the JZPO-10.4 aptamer in the presence and absence of OKT3. The JZPO10.4 aptamer was incubated with Jurkat E.6 cells in the presence of either the control antibody against CD28 (blue) or OKT3 mAb (red; Figure S5 shows the corresponding secondary antibody staining). (C) Overall conclusion from three independent $\mathrm{mAb}$ competitive binding experiments for the JZPO-10.4 aptamer. Statistical significance was evaluated using an unpaired $t$ test in GraphPad Prism (***0.0001 $\leq p \leq 0.001)$. 


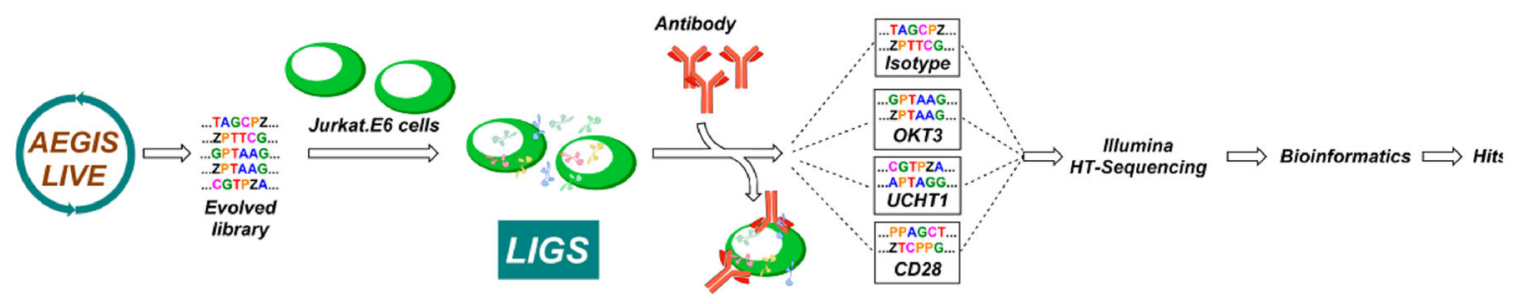

Scheme 1.

Workflow of AEGIS-LIVE-LIGS ${ }^{a}$

${ }^{a}$ AEGIS-LIVE is first employed against Jurkat.E6 cells until a partial enrichment of the AEGIS DNA aptamer library is achieved. Next, the partially enriched AEGIS-LIVE pool is divided into fractions. The first fraction, which is partially enriched with respect to Jurkat.e6 cells, is amplified via PCR and subjected to Illumina-HT sequencing. An excess of mAb (Isotype, OKT3, UCHT1, or CD 28) is then introduced into each remaining fraction, which was pre-incubated with target cells to selectively elute potential aptamers that would tend to bind to the mAb's cognate epitope. The sequences eluted by each mAb are amplified via PCR, converted to the four-letter alphabet, and subjected to Illumina-HT sequencing. Finally, sequences obtained from sequencing of each fraction were analyzed using FASTAptamer and Galaxy program, and on the basis of set criteria, specific aptamer candidates against respective epitopes on the target cells are identified. 
Table 1.

Potential Hit Aptamer Candidates Identified by Bioinformatics Analysis ${ }^{a}$

\begin{tabular}{cc}
\hline name & \multicolumn{1}{c}{ sequence $\left(\mathbf{5}^{\prime} \rightarrow \mathbf{3}^{\prime}\right.$ ) } \\
JZPO-19 & GCGPGGTATTGCTGPGGGGCCGGTAAGTGTGGGG \\
JZPU-12 & GGGGGGTTACAAPGGGGZGGPGATGTTTGCZGGGA \\
JZPU-19 & GCGPGGTAGTGPGGGCCPCCGGGGCTCAGTAGGG \\
JZPU-7 & GPGGAGCTTGGPGGGGGGGGGTAGAGTGAGGGGC \\
JZPU-18 & GCGPGTCAGTGPGGGGCCPTCGGGGTTCAGTGGGG \\
JZPU-2 & ZAGGAGPGCCTGPGGGCGGGTCTAGTGGGGAAGGA \\
JZPU-17 & GCGPGGTAGTGPGGGCCCPTCGGGGCTCAGTGGGG \\
JZPO-22 & GGTCAGGPGCTPCAGPGGGCGGGTCAATTGGGGPG \\
JZPU-1 & AAPGGTTCGGPGGGGCAGGGGGGTCGAGTGPGGGG \\
JZPO-10 & PGGAGPGGGGTAGAGTGGGGPTGGGGCTATGGGGC \\
JZPO-21 & GGTCAGGPGCTPTAGPGGGCGGGCCGGGTGGGGPG \\
JZPO-4 & ZAGGAGPGTTTGPGGTGGGTCTGGTGGGGGAGGA \\
JZPO-20 & GCGPGGTGTTGCTGPGGGGCCGGGTAGGTGCGGGG \\
JZPO-3 & ZAGAGGPGCCTGPGGGTGGGTCTAGTGGGGGAGGA \\
\hline all hits are 71 nucleotides long with two primer sequences: 5' -ATAGACTGGACTGTCGTC-3' (forward) and 5'- \\
TAGCATCGGATACAGGTC-3' (reverse).
\end{tabular}




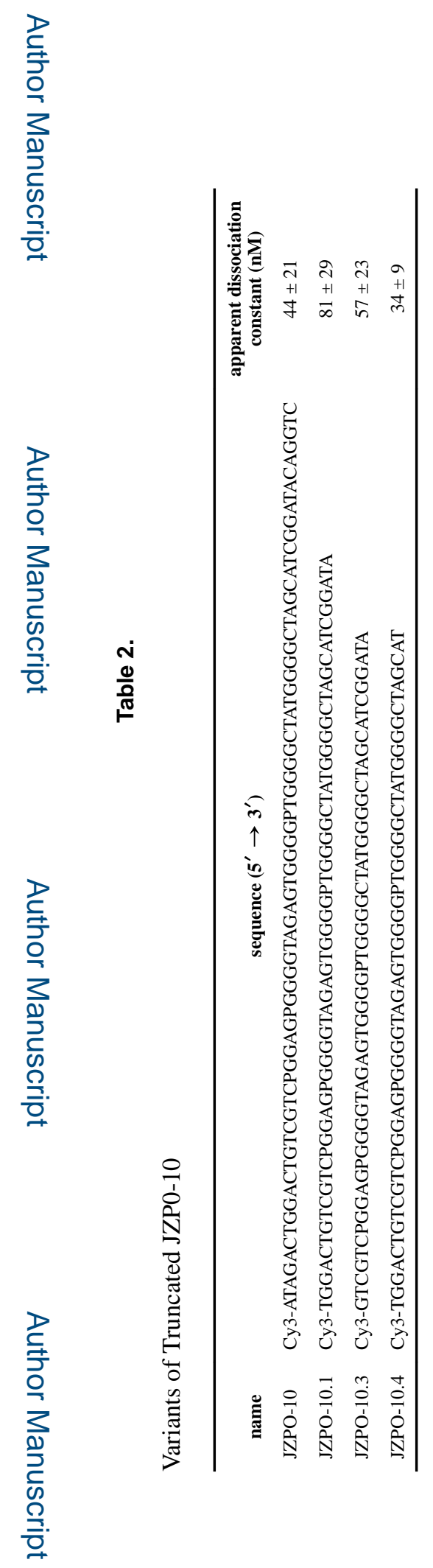

Biochemistry. Author manuscript; available in PMC 2021 February 04. 